\title{
In vitro permeation and in vivo anti-inflammatory and analgesic properties of nanoscaled emulsions containing ibuprofen for topical delivery
}

This article was published in the following Dove Press journal:

International Journal of Nanomedicine

16 February 201I

Number of times this article has been viewed

\author{
Ghassan Z Abdullah"* \\ Muthanna F Abdulkarim ${ }^{*}$ \\ Ibrahim M Salman' \\ Omar Z Ameer' \\ Mun FYam ${ }^{1,2}$ \\ Ahmed F Mutee' \\ Mallikarjun Chitneni ${ }^{3}$ \\ Elrashid S Mahdi' \\ Mahiran Basri ${ }^{4}$ \\ Munavvar A Sattar \\ Azmin M Noor ${ }^{1}$ \\ 'School of Pharmaceutical Sciences, \\ Universiti Sains Malaysia, Penang, \\ Malaysia; ${ }^{2}$ Faculty of Medicine and \\ Health Science, Universiti Putra \\ Malaysia, Selangor, Malaysia; ${ }^{3}$ School \\ of Pharmacy and Health Sciences, \\ International Medical University, Kuala \\ Lumpur, Malaysia; ${ }^{4}$ Faculty of Science, \\ Universiti Putra Malaysia, Selangor, \\ Malaysia; *The first and second \\ authors have contributed equally to \\ this work.
}

Introduction: As a topical delivery system, a nanoscaled emulsion is considered a good carrier of several active ingredients that convey several side effects upon oral administration, such as nonsteroidal anti-inflammatory drugs (NSAIDs).

Objective: We investigated the in vitro permeation properties and the in vivo pharmacodynamic activities of different nanoscaled emulsions containing ibuprofen, an NSAID, as an active ingredient and newly synthesized palm olein esters (POEs) as the oil phase.

Methodology: A ratio of 25:37:38 of oil phase:aqueous phase:surfactant was used, and different additives were used for the production of a range of nanoscaled emulsions. Carbopol ${ }^{\circledR}$ 940 dispersion neutralized by triethanolamine was employed as a rheology modifier. In some circumstances, menthol and limonene were employed at different concentrations as permeation promoters. All formulae were assessed in vitro using Franz diffusion cell fitted with full-thickness rat skin. This was followed by in vivo evaluation of the anti-inflammatory and analgesic activities of the promising formulae and comparison of the effects with that of the commercially available gel.

Results and discussion: Among all other formulae, formula G40 (Carbopol ${ }^{\circledR}$ 940-free formula) had a superior ability in transferring ibuprofen topically compared with the reference. Carbopol $^{\circledR} 940$ significantly decreased the amount of drug transferred from formula G41 through the skin as a result of swelling, gel formation, and reduction in drug thermodynamic activity. Nonetheless, the addition of $10 \% \mathrm{w} / \mathrm{w}$ of menthol and limonene successfully overcame this drawback since, relative to the reference, higher amount of ibuprofen was transferred through the skin. By contrast, these results were relatively comparable to that of formula G40. Pharmacodynamically, the G40, G45, and G47 formulae exhibited the highest anti-inflammatory and analgesic effects compared with other formulae.

Conclusion: The ingredients and the physical properties of the nanoscaled emulsions produced by using the newly synthesized POEs succeeded to deliver ibuprofen competently.

Keywords: in vivo analgesic, anti-inflammatory effects

\section{Introduction}

Skin, the biggest organ in the body that accounts for about $10 \%$ of total bodyweight, provides several functions, which are: protection, thermoregulation, transpiration, homeostasis, and sensation. ${ }^{1}$ Physiologically, skin is the thickest barrier of the body and consists of three major layers; namely, the epidermis or outer layer, the dermis, and the subcutaneous tissues or hypodermis. ${ }^{1-4}$ Stratum corneum, the most superficial layer of the epidermis, ${ }^{5,6}$ represents the nonviable part that comprises many layers of dead and nucleus-free cells, known as corneocytes. It is the main barrier for both ingress and egress of materials and/or many environmental contaminants and foreign bodies. ${ }^{7}$
Correspondence: Ghassan Z Abdullah School of Pharmaceutical Sciences, Universiti Sains Malaysia, I 1800 Minden, Penang, Malaysia

Tel +60 164092692

Email ghassanalyasiri@yahoo.com 
This property is attributed to the stratum corneum exceptional brick wall-like structure comprising corneocytes as the bricks and intercellular lipids as the mortar..$^{5,8,9}$

Ibuprofen, a nonsteroidal anti-inflammatory drug (NSAID), possesses analgesic, antipyretic and anti-inflammatory activities. As a propionic acid derivative, ibuprofen has a short half-life of only 2.2 hours and a high level (90\%-99\%) of plasma protein binding. ${ }^{10}$ Hence, its plasma concentration reaches the peak level after approximately 1-2 hours following its oral administration, with a subsequent rapid excretion in the urine. Ibuprofen is a water-insoluble drug with an acidic $\mathrm{pKa}$ value of 5.3 and high lipophilicity with a $\log P$ value of 3.6 .

It was suggested by many researchers that a relatively high partition coefficient can reduce drugs' skin permeation due to the elevated lipophilicity, which may cause them to be deposited in the skin lipid layers, particularly the stratum corneum. However, this accumulation is useful when localized effects are required. Therefore, several techniques were performed to improve the transdermal transport of ibuprofen, such as complexation with cyclodextrin, ${ }^{11}$ supersaturation, ${ }^{12,13}$ preparation of colloidal microstructures with lysinate and lecithin, ${ }^{14}$ eutectic systems produced by melting-point depression, ${ }^{15,16}$ iontophoresis, ${ }^{17}$ and the usage of surfactants and various vehicles. ${ }^{18,19}$

Nanoscaled emulsion and microemulsion possess very small droplets size, ${ }^{20-23}$ which makes them quite appealing for the topical delivery of various drugs. They have the ability to accommodate large amounts of drug due to the increased solubilization capacity, thereby enhancing the thermodynamic activity towards the skin. Furthermore, the main constituents of these biphasic systems can be combined synergistically to enhance drug flux. ${ }^{24}$

Skin hydration is known to enhance transdermal drug delivery; therefore, many efforts have been made to synthesize various compounds capable of boosting skin hydration. Palm olein esters (POEs), a modified form of palm oil, was synthesized by a Malaysian research group by reacting palm oil with olyel alcohol to produce long ester chains of the original triglyceride palm oil. It is reported that POEs have a skin hydration activity of $40.7 \%$ after 90 minutes of application. ${ }^{25}$

Terpenes, as penetration enhancers, are essential oils obtained from natural sources; they are thus classified by the United States Food and Drug Administration as safe and effective sorption promoters. Isoprene $\left(\mathrm{C}_{5} \mathrm{H}_{8}\right)$ is the building block of these materials and is usually repeated and joined together from head to tail. ${ }^{26,27}$ Terpenes, compared with surfactants and other types of enhancers, are safer, less toxic, and less irritating. ${ }^{28}$

In general, terpenes are classified, according to the number of isoprene units, into: monoterpens (C10), sesquiterpenes (C15), diterpenes (C20), sesterterpenes (C25), triterpenes (C30), and tetraterpenes (C40). Menthol and limonene are both monoterpenes, but they are chemically different. Menthol is an ester-alcohol terpene, while limonene is hydrocarbon lipophilic terpene. Terpenes act as good permeation promoters as they are highly lipophilic, able to disrupt skin lipid packing, and capable of forming eutectic mixtures. ${ }^{26,29}$

In the present study, we investigated the suitability of using these newly introduced POEs as an internal phase for topical delivery of ibuprofen in nanoscaled emulsion formulations. We further examined the effect of various concentrations and types of terpenes as permeation promoters. In view of that, attempts have been made to compare the potential activity of the formulated nanoscaled emulsions to topically deliver ibuprofen with that of the marketed formula. Experimentally, we evaluated the in vitro transfer of the prepared formulae through full-thickness rat skin using a marketed gel formula as a reference. Moreover, the in vivo anti-inflammatory and analgesic activities of the tested and the commercially available preparations were measured and compared.

\section{Materials and methods \\ Materials}

Potassium dihydrogen phosphate and sodium hydroxide were supplied by $\mathrm{R}$ and $\mathrm{M}$ Chemicals (London, UK). Orthophosphoric and hydrochloric acids were supplied by BDH (London, UK). Acetonitrile and methanol, high performance liquid chromatography (HPLC) grade, were purchased from JT Baker (Phillipsburg, NJ). The POEs were a contribution from co-researchers at the Universiti Putra Malaysia (Selangor, Malaysia). Tween 80, Tween 85, Span 20, Span 85, and sodium benzoate were purchased from Sigma-Aldrich Chemie, GmbH (Munich, Germany). Ibuprofen was supplied by Noveltek Life-Science (Tanggu, China). Menthol and limonene were supplied by Sigma-Aldrich Chemie, $\mathrm{GmbH}$ (Munich, Germany). Nurofen ${ }^{\circledR}$ \% gel was obtained by Boots Healthcare International (London, UK). All other solvents were of analytical grade.

\section{Methods}

Preparation of the nanoscaled emulsions

Preliminary studies by our research group were initially carried out to determine the best POE-surfactant-mixture compositions 
that can provide the highest drug solubility and preferred physical properties of $\mathrm{o} / \mathrm{w}$ emulsions (data not shown). This was achieved via constructing several pseudoternary phase diagrams and followed by the characterization of the selected formulae in terms of appearance, droplets size, flow properties, zeta potential, and physical stability upon standing. A few nanoscaled emulsions were chosen for further investigation. These formulae (Table 1) contained POEs as the oil phase, triethanolamine (TEA) aqueous solution $\mathrm{pH} 7.4$ as the aqueous external phase, and Tween 80 (HLB 15) as the emulsifying agent. Sodium benzoate and Carbopol ${ }^{\circledR} 940$ were used as a preservative and rheology modifier, respectively. A ratio of 25:37:38 of POEs:aqueous phase:Tween 80 was chosen for the production of pharmaceutically acceptable nanoscaled emulsions for topical delivery.

The preparation process of the nanoscaled emulsions was conducted by initially mixing the specified ratios of the oil phase (POEs) and the emulsifier in a beaker under the following conditions: mixing at a speed of $750 \mathrm{rpm}$ using low shear mixer equipped with a three-blade propeller and temperature control of $40^{\circ} \mathrm{C} \pm 1^{\circ} \mathrm{C}$ for 30 minutes. Subsequently, $5 \% \mathrm{w} / \mathrm{w}$ of ibuprofen was dissolved, and the resultant mixture was further revolved at the same speed and temperature for another 30 minutes. The external phase (pH 7.4) controlled by TEA and containing $0.20 \% \mathrm{w} / \mathrm{w}$ sodium benzoate and $0.50 \%$ w/w of Carbopol ${ }^{\circledR} 940$ was added separately drop by drop with continuous stirring for another 90 minutes. Agitation using the low shear mixer at a rotation speed of $1500 \mathrm{rpm}$ was then used for approximately $4-5$ hours to ensure the formation of homogenous nanoscaled emulsions.

\section{In vitro transport of drug through rat skin}

In this study, full thickness Wistar Kyoto rat skin was used to assess the in vitro drug transport. Franz-type diffusion cell (PermeGear, Inc, Hellertown, PA) vertically situated with an effective diffusion area of $0.636 \mathrm{~cm}^{2}$ and a receptor cell volume of $5 \mathrm{~mL}$ was used. Skin samples were obtained from the abdominal region of healthy 200-250 g male rats. All experimental procedures on animals were in accordance with the Guidelines of the Animal Ethical Committee of the Universiti Sains Malaysia (USM) and had their approval (Reference number: USM/PPSF/50 [042] Jld.2).

Rats were initially anesthetized with $60 \mathrm{mg} / \mathrm{kg}$ sodium pentobarbitone injection given intraperitoneally. The abdominal skin was first shaved using electric and hand razors and then surgically excised from the animal. The skin removal step was followed by carefully removing the adhering subcutaneous fat from the skin. To remove the extraneous debris and leachable enzymes, the cleaned skin was immersed and periodically flushed with normal saline solution for 2 hours. Finally; the pieces of cleaned skin were washed with distilled water and wrapped in aluminum foil and stored in a deep freezer at $-20^{\circ} \mathrm{C}$. After freezing, the skin was cut into $0.15 \mathrm{~cm}$ thick pieces and kept at the same temperature to be used the next day when the experiment was performed.

On the day of experimentation, the appropriate number of frozen skin pieces were thawed at room temperature and mounted between the donor and the receptor compartments of the diffusion cell with the stratum corneum side facing the donor compartment and the dermal side facing the receptor compartment. The static receptor cell was filled with $5 \mathrm{~mL}$ $0.2 \mathrm{M}$ phosphate buffer solution (PBS) pH 7.4 $4^{30}$ and kept at $37^{\circ} \mathrm{C} \pm 0.5^{\circ} \mathrm{C}$ by a circulating water jacket. The content of the receptor compartment was continuously stirred at $500 \mathrm{rpm}$ using a small magnetic bar to ensure its uniformity over the time course of the experiment.

A quantity of $100 \mathrm{mg}$ of each formulation tested was placed in the donor compartment and spread evenly on the full-thickness rat skin, and the cells were finally covered with aluminum foil. Samples of $400 \mu \mathrm{L}$ were withdrawn at predetermined time intervals of $0.5,1,2,3,4,6$, and 8 hours, and replaced with the same volume of fresh PBS pH 7.4 kept at $37^{\circ} \mathrm{C}$. Sink conditions were met in all cases and triplicate parallel determinations were performed using skin taken from

Table I Chemical composition (\% w/w) of selected nanoscaled emulsions

\begin{tabular}{|c|c|c|c|c|c|c|}
\hline \multirow[t]{2}{*}{ Formula } & \multirow{2}{*}{$\begin{array}{l}\text { Ibuprofen } \\
\text { content }\end{array}$} & \multicolumn{3}{|l|}{ Oil phase } & \multirow{2}{*}{$\begin{array}{l}\text { TEA solution } \\
\text { pH } 7.4\end{array}$} & \multirow[t]{2}{*}{ Tween $\mathbf{8 0}$} \\
\hline & & Menthol & Limonene & $\overline{\text { POEs }}$ & & \\
\hline $\mathrm{G} 40^{\mathrm{a}}$ & 5 & - & & 23.70 & 35.08 & 36.02 \\
\hline G4I & 5 & - & & 23.58 & 34.89 & 35.83 \\
\hline G44 & 5 & 5 & - & 18.58 & 34.89 & 35.83 \\
\hline G45 & 5 & 10 & - & 13.58 & 34.89 & 35.83 \\
\hline G46 & 5 & - & 5 & 18.58 & 34.89 & 35.83 \\
\hline G47 & 5 & - & 10 & 13.58 & 34.89 & 35.83 \\
\hline
\end{tabular}

Note: All formulations contain $0.20 \% \mathrm{w} / \mathrm{w}$ sodium benzoate as a preservative and $0.50 \% \mathrm{w} / \mathrm{w}$ Carbopol ${ }^{\circledR} 940$ as a rheology modifier. ${ }^{\mathrm{a} C a r b o p o l}{ }^{\circledR} 940$-free nanoscaled emulsion. Abbreviations: POE, palm olein ester; TEA, triethanolamine. 
the same rat. Dilution of samples with the HPLC mobile phase was made when necessary, and the drug content in the collected samples was then determined by a validated HPLC method modified by our research team. ${ }^{31}$

\section{Calculation of permeability parameters}

Parameters were calculated in this part of the study to compare the drug transfer and permeation properties amongst the tested formulae. Descriptions of these parameters are outlined below and include steady state flux, permeability coefficient, and enhancement ratio.

\section{Steady state flux}

Flux is defined as the rate of diffusion or transport of a substance through a permeable membrane. After reaching the steady state of drug permeation, flux was calculated using the following equation:

$$
\text { Steady state flux }\left(J_{S S}\right)=d M / S \cdot d t
$$

where $d M$ is the amount of drug that permeates through a unit cross-section area $(S)$ in a unit time $(t)$. From the above equation, it is clear that the slope of the steady state portion of the permeation curve created by plotting the cumulative amount of drug permeated in micrograms versus time in hours is the flux. ${ }^{32}$

\section{Permeability coefficient}

The quantity of ibuprofen diffused per unit area of skin $(\mathrm{dM} / \mathrm{S})$ was calculated for each time interval, and the permeability coefficient through the membrane (Kp) was determined according to the following equation:

$$
\text { Permeability coefficient }(\mathrm{Kp})=\left(J_{S S} \cdot H\right) / C_{0} \text {, }
$$

where $J_{S S}$ is the steady state flux, $H$ is the thickness of membrane used, and $C_{0}$ is the initial drug concentration.

\section{Enhancement ratio}

The enhancement ratio was calculated to find the relative enhancement in the flux of formulations evaluated with respect to reference enhancement ratio. The enhancement ratio was estimated according to the following equation:

Enhancement ratio $(\mathrm{Er})=J_{S S}$ formulation $/ J_{S s}$ reference. (3)

\section{Measurement of in vivo anti-inflammatory activity}

Healthy male Sprague Dawley rats weighing 180-200 g were used in this study. All experimental procedures on animals conformed to the Guidelines of the Animal Ethical committee of USM and had their approval (Reference number: USM/PPSF/50 [042] Jld.2). The anti-inflammatory action was evaluated by using the carrageenan-induced hind paw edema method as reported by Larson and Lombardino. ${ }^{33}$ Rats were randomly picked and divided into five groups of six animals each for administering the control (ibuprofenfree formula), formulations G40, G45, and G47, as well as the reference product (Nurofen ${ }^{\circledR} 5 \% \mathrm{Gel}$ ). The animals were housed in polypropylene cages at $25^{\circ} \mathrm{C} \pm 1{ }^{\circ} \mathrm{C}$ and $60 \% \pm 5 \%$ relative humidity, with free access to food and water.

On the test day, $100 \mathrm{mg}$ of formulations G40, G45, G47, reference, and the control were rubbed gently into the right hind paw (hairless legs) until complete disappearance of the amount applied. After 1 hour, $0.1 \mathrm{~mL}$ of $1 \% \mathrm{w} / \mathrm{v}$ carrageenan suspension was injected into the subplantar region of the right hind paws of controlled and treated groups. This was followed by measuring the edema volume via determining paw thickness at fixed time intervals of $1,2,3,4,5$, and 6 hours. All measurements were achieved at $25^{\circ} \mathrm{C} \pm 1^{\circ} \mathrm{C}$ in an air-conditioned room using a micrometer (Ozaki Ltd, Okayama, Japan). ${ }^{34,35}$ The induced swelling was measured by placing the foot of the rat in between the anvil and the spindle of the micrometer. The degree of swelling induced by carrageenan was calculated as a percentage of hind paw thickness at the intervals specified relative to their initial thickness. Mathematically, the degree of swelling was calculated as follows:

$$
\begin{aligned}
& \text { Percentage changes } \\
& \text { of hind paw thickness }
\end{aligned}=\frac{c_{t}-c}{c} \times 100 \% \text {, }
$$

where $c_{t}=$ hind paw thickness at $1,2,3,4,5$, and 6 hour intervals after injecting carrageenan. $c=$ initial hind paw thickness, ie, before the injection of carrageenan.

\section{Measurement of in vivo analgesic activity}

In this study, a procedure similar to that mentioned in the previous section was utilized with the exception of measuring the pain threshold response of the right hind paw instead of the edematous thickness. The pain threshold was measured initially before injecting the inflammatory inducer (carrageenan) and at preset time intervals of 2 and 4 hours following the application of $100 \mathrm{mg}$ of the control (ibuprofen-free formula), formulations G40, G45, and G47, as well as the reference product (Nurofen ${ }^{\circledR}$ 5\% Gel). All measurements were performed in an 
air-conditioned room at controlled temperature of $25^{\circ} \mathrm{C} \pm 1{ }^{\circ} \mathrm{C}$ using a portable pain threshold device (YMF-P1) equipped with data acquisition system (fabricated by the Department of Pharmacology, School of Pharmaceutical Sciences, USM, Malaysia). The pain threshold was measured as the pressure in grams applied on the edematous hind paw which caused the rat to withdraw the treated paw. The vocalization or the struggles of the rat were also considered as indicators for the pain threshold. ${ }^{36}$ The change in pain threshold was calculated as the difference in the pain threshold before and after the injection of carrageenan.

\section{Statistical analysis}

The statistical analysis of the data obtained was performed using SPSS software (version 16; SPSS Inc., Chicago, IL). One-way ANOVA test was used to measure the statistical difference between tested formulae, where the difference was considered statistically significant at $P<0.05$ and $P<0.001$.

\section{Results and discussion Drug transfer through rat skin}

Initially, two formulae G40 and G41 were chosen to be tested and compared with the reference formula (Nurofen ${ }^{\circledR}$ $5 \% \mathrm{Gel}$ ). This selection was based on the characterization of the results obtained at an earlier stage of this work. Formulation G40 showed the highest ibuprofen solubility $(187.33 \pm 1.40 \mathrm{mg} / \mathrm{gm})$ and the smallest droplet size $(20.9 \pm 0.46 \mathrm{~nm})$ compared with other formulations. However, this formula demonstrated poor flow properties revealed by its typically low calculated intrinsic viscosity $\left(\eta_{i}\right)$ of $11.87 \pm 0.72$ poise. Therefore, formula G40 was further modified using $0.50 \% \mathrm{w} / \mathrm{w}$ of Carbopol $^{\circledR} 940$ as a rheology modifier to produce G41. The addition of this polymer increased the calculated intrinsic viscosity of the latter formula almost 14-fold compared with the former one. Also, formula G41 showed superior flow properties ( $\eta_{i}=148.00 \pm 7.36$ poise) relative to that of the reference chosen $\left(\eta_{i}=122.98 \pm 2.44\right.$ poise $)$. The $\mathrm{pH}$ of $\mathrm{Carbopol}^{\circledR}$ 940 aqueous dispersion was kept constant at a value of 7.4 using TEA, which was previously reported to have a positive influence on the gelling and swelling characteristics of the Carbopol ${ }^{\circledR}$ resins. ${ }^{37-39}$ This can in turn improve the rheologymodification properties of these polymers. Despite a possible reduction in active ingredient permeation properties, the polymer provides more resistance toward drug movement through the polymer-gel network. Therefore, the release profile of both formulations (G40 and G41) was evaluated and compared with that of the reference.

Figure 1 and Table 2 show the release profile of formulae G40, G41, and the reference formula and their calculated permeability parameters, respectively. Overall, it is apparent that formula G40 demonstrated faster and higher release profile compared with Nurofen ${ }^{\circledR} 5 \%$ Gel after 8 hours. Formula G41 had a higher drug transport profile than that of the reference over the first 3 hours of the experiment (the pre-steady state period). After 4 hours, the quantity of drug released from both formulae was almost equal, with subsequently higher ibuprofen release from Nurofen ${ }^{\circledR} 5 \% \mathrm{Gel}$ upon attaining the steady state condition.

Diffusion of the drug incorporated into an o/w emulsion or nanoscaled emulsion system is affected by the partitioning of the drug between the internal oil phase and the external aqueous phase. This means that the drug must diffuse from the internal phase to the external phase where the drug molecules are free to be released. Hence, when drug solubility, the driving force for the enhancement of drug release, is increased in the external phase, it is likely that an improvement in its partitioning from the internal phase to the external phase is observed.

Based on our results, formula G40 (Carbopol ${ }^{\circledR}$-free formula) showed higher fluidity compared with the other formulations tested. This makes ibuprofen thermodynamic activity and release from the oil phase and its subsequent partitioning into the aqueous phase easier and faster. No gel-forming additive is included in this formula, which is usually able to network and structure the external phase that impedes the free drug movement and penetration. The

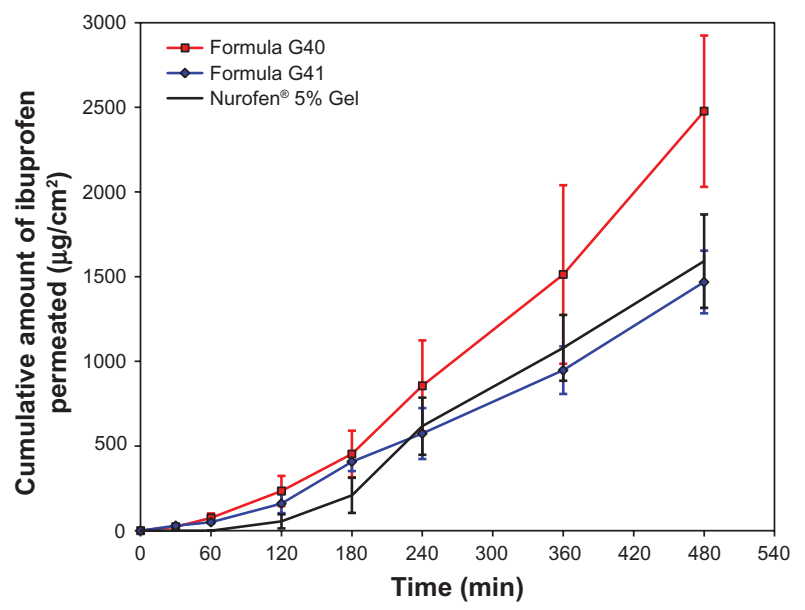

Figure I Cumulative mean of in vitro permeation profiles of ibuprofen from formulations G40, G4I, and reference Gel through rat skin.

Note: All data is presented as mean \pm standard deviation $(n=3)$. 
Table 2 Permeability parameters of evaluated formulations

\begin{tabular}{lllll}
\hline Formulation & $\begin{array}{l}\text { Flux } \\
\left(\mu \mathrm{g} / \mathbf{c m}^{2} \mathbf{~ h r}\right)\end{array}$ & $\begin{array}{l}\text { Percentage of } \\
\text { ibuprofen permeated }\end{array}$ & $\begin{array}{l}\text { Permeability } \\
\text { coefficient }(\mathbf{c m} / \mathbf{h r})\end{array}$ & $\begin{array}{l}\text { Enhancement } \\
\text { ratio }\end{array}$ \\
\hline G40 & $10.62 \pm 1.364^{\mathrm{a}}$ & $25.64 \pm 3.587$ & $0.203 \pm 2.6 \times 10^{-5}$ & 1.66 \\
G4I & $5.86 \pm 0.259$ & $14.06 \pm 1.755$ & $0.112 \pm 4.9 \times 10^{-6}$ & 0.92 \\
G44 & $7.31 \pm 1.142$ & $18.77 \pm 3.928$ & $0.139 \pm 2.2 \times 10^{-5}$ & 1.15 \\
G45 & $9.37 \pm 2.036^{\mathrm{a}}$ & $21.93 \pm 2.867$ & $0.134 \pm 7.9 \times 10^{-6}$ & 1.47 \\
G46 & $7.02 \pm 0.415$ & $17.78 \pm 0.558$ & $0.179 \pm 3.9 \times 10^{-5}$ & 1.10 \\
G47 & $8.72 \pm 0.036^{\mathrm{a}}$ & $22.35 \pm 0.665$ & $0.166 \pm 6.9 \times 10^{-7}$ & 1.37 \\
Nurofen ${ }^{\circledast} 5 \% \mathrm{Gel}$ & $6.38 \pm 0.734$ & $16.58 \pm 3.325$ & $0.122 \pm 1.4 \times 10^{-5}$ & - \\
\hline
\end{tabular}

Notes: All data is presented as mean \pm standard deviation $(n=3)$. a $<<0.05$ versus Nurofen ${ }^{\circledR} 5 \%$ Gel.

physical properties of this nanoscaled emulsion may positively influence ibuprofen permeation (very small droplets size). ${ }^{40}$ The POEs were found to have an occlusive effect that can induce the hydration of the skin combined with the hydration effect of aqueous phase leading to an increase in the porosity of the skin. ${ }^{25}$ Additional hydration of the stratum corneum augments drug permeation by loosening of the tightly-packed lipid lamellae. ${ }^{41}$ Nonionic surfactants, like Tween 80, were found to act as permeation enhancers through different skin models. They can disturb the lipid bilayer of the stratum corneum, making it a less effective barrier against the permeation of many drugs. ${ }^{42-44}$

By contrast, both formula G41 and the reference are gels in their composition since they contain $\mathrm{Carbopol}^{\circledR} 940$ and hydroxyethyl cellulose as gelling agents, respectively. Both polymers are swellable upon exposure to an aqueous environment. Acrylic acid-based polymers are reported to have high swelling capabilities. ${ }^{45}$ Also, Nurofen ${ }^{\circledR} 5 \%$ Gel contains high concentrations of benzyl alcohol and isopropyl alcohol in its composition, which can act dually as preservatives and penetration enhancers. As a result, the first three hours of the experiment showed a little higher ibuprofen release from formula G41 compared with the reference, which indicated a good release of the drug from the oil phase to the aqueous phase and thereafter a good penetration. Higher ibuprofen penetration from this formula may be attributed to the effects of POEs, Tween 80 , the physical properties of the preparation, and the incompletely formed Carbopol ${ }^{\circledR}$ 940 gel network. Furthermore, ibuprofen solubility studies showed that its oil solubility increased drastically upon adding the surfactant (Tween 80) at all ratios used (data not shown). Similarly, ibuprofen aqueous solubility rose dramatically when the $\mathrm{pH}$ of the aqueous solution increased, with the highest solubility in PBS pH 7.4. Thus, ibuprofen molecules are expected to be mainly integrated in the oil phase and at the oil-water interface. ${ }^{46}$ It is also suggested that ibuprofen diffusion to the external phase should be faster at PBS pH 7.4 as its solubility in this buffer is about 5 and 38 times higher than in PBS pH 6.0 and 4.0, respectively. Therefore, the partition of ibuprofen from POEs to PBS pH 7.4 would also be expected to be about 5 and 38 times higher in PBS pH 7.4 compared with PBS pH 6.0 and 4.0, respectively. Higher solubility and partitioning would be the driving force for the drug to be released to the external phase and transferred through the membrane at a faster rate.

These postulations were in a good correlation with what was reported by Hadgraft and Valenta. ${ }^{47}$ They found that a gradual increase in the $\mathrm{pH}$ value of the external phase of topical or transdermal preparations containing ibuprofen can influence its skin permeation. Another study also demonstrated a 10-fold increase in the flux of several NSAIDs, including ibuprofen, upon a gradual increase in the $\mathrm{pH}$ value of the topical preparation. ${ }^{44}$ These studies assumed that enhancing the ionization of NSAIDs can lead to an increase in their ion pairing capabilities with the external components of skin just like different types of fatty acids. The produced ion-pairs are usually more lipophilic than the unjoined drug, which lead to an augmentation in drug penetration via the skin. ${ }^{48-50}$ Another hypothesis that explains the increased drug transfer is connected to the transfer rates of ionized drugs, which are predominantly higher at high $\mathrm{pH}$ values, through the ionic channels oriented into the lipid bilayer of the stratum corneum. ${ }^{47}$

The release patterns were inversed after 4 hours of the experiment. This effect may be attributed to excessive Carbopol $^{\circledR} 940$ swelling which imparts excessive impedance to ibuprofen transfer through the skin. This was further confirmed by measuring the thickness of the samples present in the donor compartment. The thickness of formula G41 was almost doubled as it increased from $3.4 \mathrm{~mm}$ to $6.1 \mathrm{~mm}$, whereas the thickness of the reference formula remained unchanged at $3.5 \mathrm{~mm}$.

Our aim was to formulate a pharmaceutically acceptable nanoscaled emulsion with advanced flow and 
penetration properties compared with the reference formula. Rheologically, formula G40 failed to achieve the proposed tasks; on the other hand, formula G41 had overall permeation properties that were less than that of the reference formula. Therefore, further modification of this formula was required.

The modification of this formula involved the addition of two different types of penetration enhancers; namely, menthol and limonene. Table 1 shows the composition of the modified forms of formula G41 that were denoted as G44-G47. These formulae were prepared using the same procedure described previously. The single difference is that two different concentrations ( $5 \%$ and $10 \% \mathrm{w} / \mathrm{w})$ of menthol or limonene were mixed initially with POEs to produce the oil phase. The nanoscaled emulsion preparation process was then performed using the very same aforementioned steps. At all concentrations used, these penetration promoters were found to have no effect on the retention time of the drug in the HPLC chromatogram.

Many studies have demonstrated the effectiveness of terpenes as penetration enhancers in general and menthol and limonene in particular. ${ }^{26}$ Therefore, menthol and limonene were used at two different concentrations to modify the nanoscaled emulsion (formula G41).

Figure 2 and Table 2 illustrate the release profile and the calculated permeation parameters of the reference formula and formulations G44-G47, respectively. Looking at these results, it can be seen that using $5 \% \mathrm{w} / \mathrm{w}$ of menthol in formula G44 and 5\% w/w of limonene in formula G46 improved the release or permeation properties of ibuprofen. All parameters related to these two formulations, including

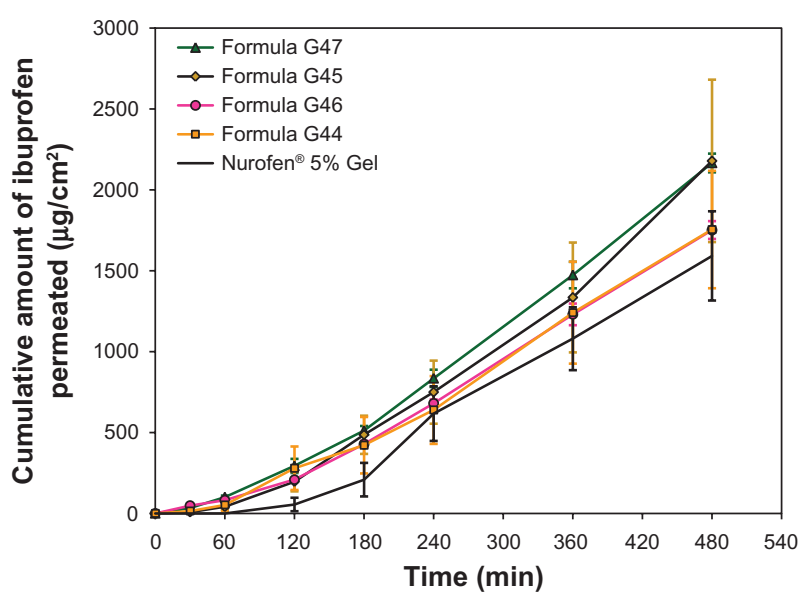

Figure 2 Cumulative mean of in vitro permeation profiles of ibuprofen from formulations G44-G47 and reference Gel through rat skin.

Note: All data is presented as mean \pm standard deviation $(n=3)$. flux, cumulative amount of ibuprofen released, permeability coefficient, and enhancement ratio, were increased compared with formula G41 and the reference.

Nevertheless, the improvement in the flux value of formulae G44 and G46 was statistically insignificant from formula G41 (enhancer-free formula) and the reference formula. On the other hand, higher concentrations of these promoters created an improvement in the release patterns of formulae G45 and G47 containing 10\% w/w of menthol and limonene, respectively. Statistically, the flux values of formulae G45 and G47 were significantly $(P<0.05)$ higher than those of the reference, G41, G44, and G46, but not from that of formula G40. In other words, $10 \% \mathrm{w} / \mathrm{w}$ of menthol or limonene as permeation promoters succeeded to improve ibuprofen transport across rat skin to a level that is higher than other formulations except for formula G40 (Carbopol ${ }^{\circledR}$-free and enhancer-free nanoscaled emulsion). Therefore, it can be suggested that $10 \% \mathrm{w} / \mathrm{w}$ of these promoters is sufficient to disrupt or disorder rat skin fat layers allowing higher amounts of ibuprofen to pass through.

Formulations G40, G45, and G47 were further evaluated by measuring their pharmacodynamic properties and comparing them to that of the reference.

\section{Measurement of in vivo anti-inflammatory activity}

From Figure 3, it is obvious that all formulae tested had a potent anti-inflammatory effect, since a significant $(P<0.05)$ difference was obtained compared with the placebo formula at all time intervals. After 6 hours, formulae G40, G45, and G47 demonstrated significantly

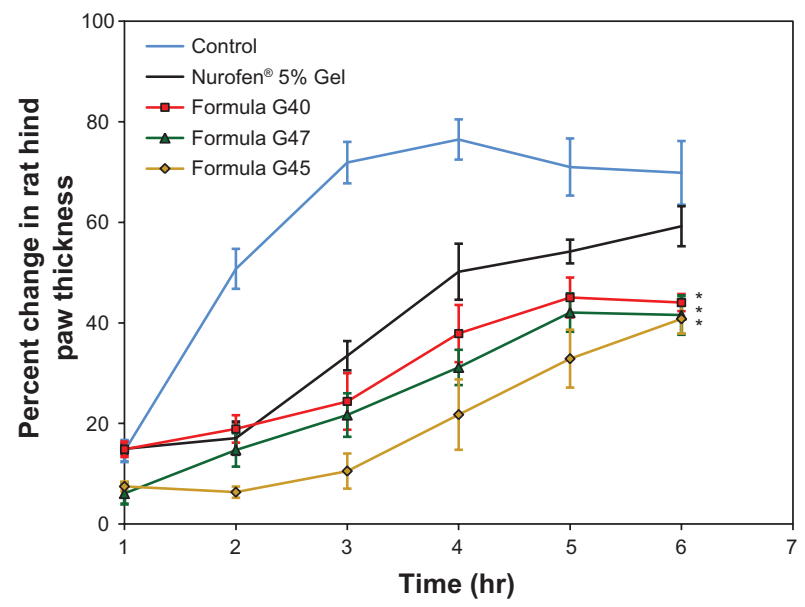

Figure 3 Anti-inflammatory effects of various formulations comprising ibuprofen, applied topically on rat hind paw edema at I,2,3,4,5, and 6 hours after administration of carrageenan.

Note: All data is presented as mean \pm standard error of the mean $(n=6)$. 
$(P<0.05)$ higher anti-inflammatory activity compared with the negative control and the reference formula, with the strongest effect attained by formula G45. This can be explained on the basis that the flux values (steady state flux that was achieved after 4 hours) of formulations G40, G45, and G47 were marginally higher compared with the reference formula, with an enhancement ratio of 1.66, 1.47, and 1.37 , respectively. Thus, the difference in the anti-inflammatory activity among these formulae and the reference was achievable only after some time when the amount of permeated ibuprofen was sufficient to produce a significant difference. Higher permeability indicates the presence of a higher amount of ibuprofen available to generate the antiinflammatory reaction at the area of injection.

\section{Measurement of in vivo analgesic activity}

This study showed a good correlation between the analgesic and anti-inflammatory effects of all formulae tested. It was obvious from the data presented in Figure 4 that all formulations had a markedly $(P<0.001)$ higher analgesic effect compared with the placebo preparation. After 2 hours of observation, no significant difference in the analgesic activity was achieved amongst formulae G40, G45, G47, and the reference. As the time progressed, the analgesic activity of the produced nanoscaled emulsions (G40, G45, and G47) became significantly $(P<0.001)$ stronger than that of the reference and the control. These results were in tandem with the anti-inflammatory effects of these formulations whereby permeation of more ibuprofen could have been triggered after a certain period of time. As the amount of ibuprofen

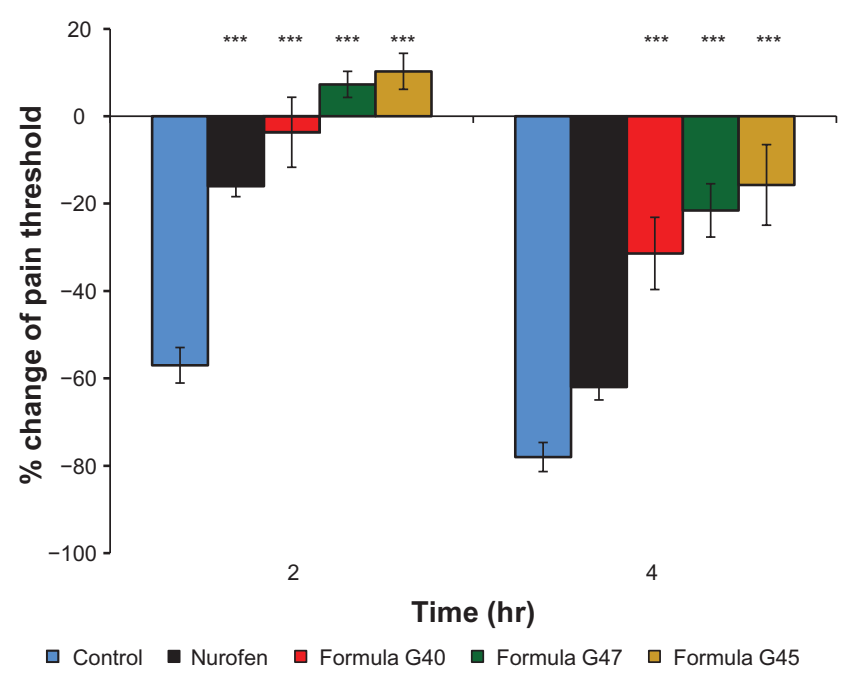

Figure 4 Analgesic effects of various formulations comprising ibuprofen, applied topically on rat hind paw edema at 2 and 4 hours after administration of carrageenan. Note: All data is presented as mean \pm standard error of the mean $(n=6)$. increases, its inhibition to the activity of prostaglandins becomes more efficient. Prostaglandins play an important role in promoting the signs and symptoms of inflammation and in sensitizing terminal afferent $\mathrm{C}$-fibers in the periphery and enhancing the response of these fibers to algesic stimuli resulting in hyperalgesia. ${ }^{51}$ The prevention of cyclooxygenase enzyme and prostaglandin synthesis can rapidly reverse hyperalgesia and pain induction. ${ }^{52}$ After 4 hours, the analgesic activity of ibuprofen in all formulations was in the following order: G45 $>$ G47 $>$ G40 $>$ reference. This could be due to the size, solubility, partition coefficient, and change in permeability of ibuprofen from the nanoscaled emulsions.

\section{Conclusion}

POEs, Tween 80, and TEA aqueous solution $\mathrm{pH} 7.4$ were suitable to formulate ibuprofen as a pharmaceutically acceptable nanoscaled emulsion for topical delivery. The selected ratio was capable of containing the desired drug concentration employed topically. Carbopol-free formula G40 showed the highest drug-transport rate or permeation flux at steady state over the period of examination through full-thickness rat skin. This could be due to its minute droplet size, synergistic effect attained by the formulation components, and the absence of gel-forming agents.

Carbopol $^{\circledR} 940$ at a concentration of $0.50 \% \mathrm{w} / \mathrm{w}$ was able to undermine the enhancing effects accomplished by the additives of formula G40 and reduced the release of ibuprofen from formula G41 to a point that is slightly less than the reference.

Lower concentrations $(5 \% \mathrm{w} / \mathrm{w})$ of the penetration promoters menthol and limonene were sufficient to increase ibuprofen flux to a level that is comparable to that of the reference. Higher percentages of these enhancers (menthol and limonene) equal to $10 \% \mathrm{w} / \mathrm{w}$ were effectively efficient to extend the transport of ibuprofen through rat skin to a position almost equal to that of formula G40 and higher than that of the reference. This is perhaps due to their elevated lipophilicity, skin lipid texture disrupting effect, and eutectic mixture formation.

The analgesic and anti-inflammatory effects of ibuprofen produced as nanoscaled emulsions in the form of formulations G40, G45, and G47 were higher compared with the marketed reference (Nurofen ${ }^{\circledR}$ 5\% Gel). The enhanced action may be ascribed to the combined effects of the small droplets size and composition of these formulae along with the increased drug solubility, partitioning into the aqueous phase of dosage form utilized, and permeability through the skin. 


\section{Acknowledgments}

The authors thank the Institute of Postgraduate Studies, Universiti Sains Malaysia, and the Biopharmacy Co-operative Center for providing financial assistance.

\section{Disclosure}

The authors report no conflicts of interest in this work.

\section{References}

1. Ventre M, Mollica F, Netti PA. The effect of composition and microstructure on the viscoelastic properties of dermis. J Biomech. 2009; 42(4):430-435.

2. Hendriks FM, Brokken D, Oomens CWJ, Bader DL, Baaijens FPT. The relative contributions of different skin layers to the mechanical behavior of human skin in vivo using suction experiments. Med Eng Phys. 2006;28(3):259-266.

3. Kaur IP, Kapila M, Agrawal R. Role of novel delivery systems in developing topical antioxidants as therapeutics to combat photoageing. Ageing Res Rev. 2007;6(4):271-288.

4. Darlenski R, Sassning S, Tsankov N, Fluhr JW. Non-invasive in vivo methods for investigation of the skin barrier physical properties. Eur $J$ Pharm Biopharm. 2009;72(2):295-303.

5. Marjukka Suhonen TA, Bouwstra J, Urtti A. Chemical enhancement of percutaneous absorption in relation to stratum corneum structural alterations. J Control Release. 1999;59(2):149-161.

6. Makrantonaki E, Zouboulis CC. The skin as a mirror of the aging process in the human organism - state of the art and results of the aging research in the German National Genome Research Network 2 (NGFN-2). Exp Gerontol. 2007;42(9):879-886.

7. Nakazawa H, Yamagishi A, Imai T, et al. Study on regional differences of stratum corneum structure in human skin by electron diffraction. Chem Phys Lipids. 2008;154:S27-S27.

8. Barry BW. Novel mechanisms and devices to enable successful transdermal drug delivery. Eur J Pharm Sci. 2001;14(2):101-114.

9. Al-Saidan SM. Transdermal self-permeation enhancement of ibuprofen J Control Release. 2004;100(2):199-209.

10. Beetge E, Du Plessis J, Müller DG, Goosen C, Van Rensburg FJ. The influence of the physicochemical characteristics and pharmacokinetic properties of selected NSAID's on their transdermal absorption. Int $J$ Pharm. 2000;193(2):261-264.

11. Godwin DA, Wiley CJ, Felton LA. Using cyclodextrin complexation to enhance secondary photoprotection of topically applied ibuprofen. Eur J Pharm Biopharm. 2006;62(1):85-93.

12. Iervolino M, Raghavan SL, Hadgraft J. Membrane penetration enhancement of ibuprofen using supersaturation. Int J Pharm. 2000;198(2): 229-238.

13. Iervolino M, Cappello B, Raghavan SL, Hadgraft J. Penetration enhancement of ibuprofen from supersaturated solutions through human skin. Int J Pharm. 2001;212(1):131-141.

14. Stoye I, SchrDer K, Müller-Goymann CC. Transformation of a liposomal dispersion containing ibuprofen lysinate and phospholipids into mixed micelles - physico-chemical characterization and influence on drug permeation through excised human stratum corneum. Eur J Pharm Biopharm. 1998;46(2):191-200.

15. Stott PW, Williams AC, Barry BW. Eutectic formulations of ibuprofen to enhance transdermal permeation. Eur J Pharm Sci. 1996;4(1): S147-S147.

16. Stott PW, Williams AC, Barry BW. Transdermal delivery from eutectic systems: enhanced permeation of a model drug, ibuprofen. $J$ Control Release. 1998;50(1-3):297-308.

17. Santi P, Nicoli S, Colombo G, et al. Post-iontophoresis transport of ibuprofen lysine across rabbit ear skin. Int J Pharm. 2003;266(1-2): 69-75.
18. Park E-S, Chang S-Y, Hahn M, Chi S-C. Enhancing effect of polyoxyethylene alkyl ethers on the skin permeation of ibuprofen. Int J Pharm. 2000;209(1-2):109-119.

19. Brown MB, Hanpanitcharoen M, Martin GP. An in vitro investigation into the effect of glycosaminoglycans on the skin partitioning and deposition of NSAIDs. Int J Pharm. 2001;225(1-2): 113-121.

20. Sznitowska M, Janicki S, Dabrowska EA, Gajewska M. Physicochemical screening of antimicrobial agents as potential preservatives for submicron emulsions. Eur J Pharm Sci. 2002;15(5):489-495.

21. Pey CM, Maestro A, Solé I, González C, Solans C, Gutiérrez JM. Optimization of nano-emulsions prepared by low-energy emulsification methods at constant temperature using a factorial design study. Colloids Surf A Physicochem Eng Asp. 2006;288(1-3):144-150.

22. Cai H, An X, Shen W. Effects of the dispersed droplet sizes on the critical behavior of pseudobinary microemulsion. Chin Sci Bull. 2007; 52(8):1139-1141.

23. Hickey S, Hagan SA, Kudryashov E, Buckin V. Analysis of phase diagram and microstructural transitions in an ethyl oleate/water/ Tween 80/Span 20 microemulsion system using high-resolution ultrasonic spectroscopy. Int J Pharm. 2010;388(1-2):213-222.

24. Kreilgaard M. Assessment of cutaneous drug delivery using microdialysis. Adv Drug Deliv Rev. 2002;54(1):S99-S121.

25. Keng PS, Basri M, Zakaria MRS, et al. Newly synthesized palm esters for cosmetics industry. Ind Crops Prod. 2009;29(1):37-44.

26. Aqil M, Ahad A, Sultana Y, Ali A. Status of terpenes as skin penetration enhancers. Drug Discov Today. 2007;12(23-24):1061-1067.

27. Dos Anjos JLV, Alonso A. Terpenes increase the partitioning and molecular dynamics of an amphipathic spin label in stratum corneum membranes. Int J Pharm. 2008;350(1-2):103-112.

28. Kang L, Yap CW, Lim PFC, et al. Formulation development of transdermal dosage forms: Quantitative structure-activity relationship model for predicting activities of terpenes that enhance drug penetration through human skin. J Control Release. 2007;120(3):211-219.

29. Brain KR, Green DM, Dykes PJ, Marks R, Bola TS. The role of menthol in skin penetration from topical formulations of ibuprofen $5 \%$ in vivo. Skin Pharmacol Physiol. 2006;19(1):17-21.

30. Santoyo S, Arellano A, Ygartua P, Martn C. In vitro percutaneous absorption of piroxicam through synthetic membranes and abdominal rat skin. Pharm Acta Helv. 1996;71(2):141-146.

31. Abdullah GZ, Abdulkarim MF, Salman IM, et al. HPLC method modification and validation for quantification of ibuprofen. Int J Drug Delivery. 2010; In press.

32. Wagner H, Kostka K-H, Lehr C-M, Schaefer UF. Interrelation of permeation and penetration parameters obtained from in vitro experiments with human skin and skin equivalents. $J$ Control Release. 2001;75(3): 283-295.

33. Larson DL, Lombardino JG. The topical anti-iflammatory effects of piroxicam in rodents. Agents Actions. 1980;10(3):246-252.

34. Sharma JN, Samud AM, Asmawi MZ. Comparison between plethysmometer and micrometer methods to measure acute paw oedema for screening anti-inflammatory activity in mice. Inflammopharmacology. 2004;12(1):89-94

35. Pénzes T, Blazs G, Aigner Z, Falkay G, Eros I. Topical absorption of piroxicam from organogels - in vitro and in vivo correlations. Int $J$ Pharm. 2005;298(1):47-54.

36. Iwalewa EO, Iwalewa OJ, Adeboye JO. Analgesic, antipyretic, anti-inflammatory effects of methanol, chloroform and ether extracts of Vernonia cinerea less leaf. J Ethnopharmacol. 2003;86(2-3):229-234.

37. Lu G, Jun HW. Diffusion studies of methotrexate in carbopol and poloxamer gels. Int J Pharm. 1998;160(1):1-9.

38. Fresno MJC, Ramírez AD, Jiménez MM. Systematic study of the flow behaviour and mechanical properties of Carbopol ${ }^{\circledR}$ Ultrez $^{\mathrm{TM}}$ 10 hydroalcoholic gels. Eur J Pharm Biopharm. 2002;54(3):329-335.

39. Lubrizol Advanced Materials Inc. Neutralizing Carbopol ${ }^{\circledR}$ and Pemulen ${ }^{\mathrm{TM}}$ polymers in aqueous and hydroalcoholic systems. Cleveland, OH: The Lubrizol Corporation; 2009. 
40. Hadgraft J. Skin, the final frontier. Int J Pharm. 2001;224(1-2):1-18.

41. Walters KA, Hadgraft J, editors. Pharmaceutical Skin Penetration Enhancement. New York, NY: Marcel Dekker; 1993.

42. Okuyama H, Ikeda Y, Kasai S, Imamori K, Takayama K, Nagai T. Influence of non-ionic surfactants, $\mathrm{pH}$ and propylene glycol on percutaneous absorption of piroxicam from cataplasm. Int J Pharm. 1999; 186(2):141-148.

43. López A, Llinares F, Cortell C, Herráez M. Comparative enhancer effects of $\operatorname{Span}^{\circledR} 20$ with Tween ${ }^{\circledR} 20$ and Azone ${ }^{\circledR}$ on the in vitro percutaneous penetration of compounds with different lipophilicities. Int J Pharm. 2000;202(1-2):133-140.

44. Shin S-C, Cho C-W, Oh I-J. Effects of non-ionic surfactants as permeation enhancers towards piroxicam from the poloxamer gel through rat skins. Int J Pharm. 2001;222(2):199-203.

45. Abdullah GZ, Abdulkarim MF, Chitneni M, et al. Preparation and in vitro evaluation of mebeverine $\mathrm{HCl}$ colon-targeted drug delivery system. Pharm Dev Technol. April 30, 2010. [Epub ahead of print].

46. Liu R, editor. Water-insoluble Drug Formulation. New York, NY: CRC Press; 2000.
47. Hadgraft J, Valenta C. pH, pKa and dermal delivery. Int J Pharm. 2000; 200(2):243-247.

48. Hadgraft J, Plessis JD, Goosen C. The selection of non-steroidal anti-inflammatory agents for dermal delivery. Int J Pharm. 2000; 207(1-2):31-37.

49. Hadgraft J, Walters KA, Wotton PK. Facilitated percutaneous absorption: a comparison and evaluation of two in vitro models. Int $J$ Pharm. 1986;32(2-3):257-263.

50. Green PG, Hadgraft J. Facilitated transfer of cationic drugs across a lipoidal membrane by oleic acid and lauric acid. Int J Pharm. 1987; 37(3):251-255.

51. Veiga APC, Duarte IDG, Vila MNA, Motta PCGD, Tatsuo MAKF, Francischi JN. Prevention by celecoxib of secondary hyperalgesia induced by formalin in rats. Life Sci. 2004;75(23):2807-2817.

52. Zhang Y, Shaffer A, Portanova J, Seibert K, Isakson PC. Inhibition of cyclooxygenase-2 rapidly reverses inflammatory hyperalgesia and prostaglandin E2 production. J Pharmacol Exp Ther. 1997;283(3): 1069-1076.
International Journal of Nanomedicine

\section{Publish your work in this journal}

The International Journal of Nanomedicine is an international, peerreviewed journal focusing on the application of nanotechnology in diagnostics, therapeutics, and drug delivery systems throughout the biomedical field. This journal is indexed on PubMed Central, MedLine, CAS, SciSearch $\AA$, Current Contents ${ }^{\circledR} /$ Clinical Medicine,

\section{Dovepress}

Journal Citation Reports/Science Edition, EMBase, Scopus and the Elsevier Bibliographic databases. The manuscript management system is completely online and includes a very quick and fair peer-review system, which is all easy to use. Visit http://www.dovepress.com/ testimonials.php to read real quotes from published authors. 